\title{
BMJ Open Determinants of contraceptive use among sexually active unmarried adolescent girls and young women aged 15-24 years in Ghana: a nationally representative cross-sectional study
}

\author{
Felix Boakye Oppong (D) , ${ }^{1}$ Divine Darlington Logo, ${ }^{2}$ Senyo Yao Agbedra, ${ }^{3}$ \\ Anthony Agyapong Adomah, ${ }^{1}$ Seidu Amenyaglo, ${ }^{4}$ Kingsley Arhin-Wiredu, ${ }^{3}$ \\ Samuel Afari-Asiedu, ${ }^{5}$ Kenneth Ayuurebobi Ae-Ngibise ${ }^{5}$
}

To cite: Oppong FB, Logo DD, Agbedra SY, et al. Determinants of contraceptive use among sexually active unmarried adolescent girls and young women aged 15-24 years in Ghana: a nationally representative crosssectional study. BMJ Open 2021;11:e043890. doi:10.1136/ bmjopen-2020-043890

- Prepublication history for this paper is available online. To view these files, please visit the journal online (http://dx.doi. org/10.1136/bmjopen-2020043890).

Received 28 August 2020 Revised 24 January 2021 Accepted 26 January 2021

Check for updates

(c) Author(s) (or their employer(s)) 2021. Re-use permitted under CC BY-NC. No commercial re-use. See rights and permissions. Published by BMJ.

For numbered affiliations see end of article.

Correspondence to

Felix Boakye Oppong; atomistic4u@gmail.com

\section{ABSTRACT}

Objective There is a decline in contraceptive use among sexually active unmarried young women in Ghana. This study assessed the prevalence of contraceptive knowledge and use, and the determinant of contraceptive use among sexually active unmarried young women in Ghana.

Design This was a nationally representative crosssectional survey, using data from the 2017 Ghana Maternal Health Survey. Weighted logistic regression was used to assess the association between background and obstetric characteristics of young women and contraceptive use. Setting Ghana.

Participants A total of 809 sexually active unmarried adolescent girls (15-19 years) and young women (20-24 years).

Primary and secondary outcome measures Knowledge and use of both modern and traditional contraceptive methods.

Results Knowledge of at least one modern and traditional contractive method was $99.8 \%$ and $95.0 \%$, respectively.

The prevalence of contraceptive use was $43 \%$-with $34 \%$ modern and $9 \%$ traditional methods. From the unadjusted analyses, age $(p=0.002)$, past pregnancy $(p<0.001)$, abortion in the past 5 years $(p=0.007)$ and history of childbirth $(p=0.025)$ were independently associated with contraceptive use, whereas education $(p=0.072)$, place of residence $(p=0.702)$, household wealth $(p=0.836)$ and age at first sex $(p=0.924)$ were not independently associated with contraceptive use. In the adjusted analysis, contraceptive use was significantly higher among respondents with secondary education compared with those with primary education (OR $2.43,95 \% \mathrm{Cl} 1.31$ to $4.49, p=0.017$ ), and was higher among respondents with a history of pregnancy $(\mathrm{OR} 2.13,95 \% \mathrm{Cl} 1.48$ to 3.06 , $p<0.001)$.

Conclusion There is a significant gap between knowledge and use of contraceptives among the study population. While intensifying knowledge of adolescents and young women on contraceptives, adolescent-friendly corners should be established at vantage points to increase utilisation and to prevent societal stigma on young women who access contraceptives services.
Strengths and limitations of this study

This is the first known study to explore the predictors of contraceptive use specifically among sexually active unmarried young women in Ghana, using nationally representative data.

- The data used in this study are representative of all sexually active unmarried adolescent girls and young women aged 15-24 years in Ghana.

- Even though data on contraceptive use were retrospectively collected, by including sexually active respondents (those who had sexual intercourse within 30 days of the survey), recall bias was significantly minimised.

- The findings of this study can only be generalised to sexually active unmarried adolescent girls and young women aged 15-24 years in Ghana.

\section{INTRODUCTION}

Improving adolescent and youth sexual and reproductive health (AYSRH) is important in preventing unintended pregnancies (UP), sexually transmitted infections and unsafe abortion. ${ }^{1}$ In recent years, there has been a significant improvement in the outcomes of AYSRH in sub-Saharan Africa (SSA), including a decline in child marriage, ${ }^{2}$ adolescent fertility rate, increase in school enrolment and contraceptive use. ${ }^{3}$ Despite this improvement, there remains disproportionately low AYSRH outcomes in SSA compared with other parts of the world, with the region having the highest adolescent pregnancy rate and the lowest rate of contraceptive use. ${ }^{4}$

Notwithstanding the increase in contraceptive use observed among young unmarried African women aged 15-24 years (from 23\% for the period 1996-2000, compared with $33 \%$ for the period 2011-2015), ${ }^{5}$ research from 
several countries in the region have shown that there is a significant unmet need for contraception among adolescents in SSA. ${ }^{6-9}$ Particularly, in about $30 \%$ of all countries in SSA, two out of every five births among adolescents are unplanned. ${ }^{10}$ Studies from Ghana have also shown that, most young women with a history of pregnancy would have used contraception to prevent those pregnancies if the contraception were available. ${ }^{78}$

In Ghana, about $30 \%$ of all pregnancies are unintended, with a significantly higher prevalence among adolescents (70\%) compared with adults. ${ }^{11}$ Adolescents who become pregnant face a multitude of health, educational and social consequences including societal disapproval, which mostly results in stigma, discrimination and social rejection. ${ }^{12}$ UP among young females also result in high school drop-out rates and truncates future development. In a study conducted in Chorkor, a fishing community in Ghana's Capital, $86 \%$ of the 50 teenage pregnant girls who were involved in the study had dropped out of school. ${ }^{13}$ It is noteworthy that most UPs end in induced abortions, ${ }^{14-16}$ with a significant number being unsafe abortions. ${ }^{17}$ In Ghana, because abortion is not entirely permitted by law-unless the pregnancy was as a result of rape, defilement or incest, or the pregnancy poses a significant risk to the mother and or unborn baby, ${ }^{18}$ unsafe abortion is common. Contraception use is undoubtedly very important in preventing UPs, unsafe abortions and abortion-related complications.

Data from the 2017 Ghana Maternal Health Survey (GMHS) report $35.6 \%$ and $48.8 \%$ use of contraceptives among sexually active unmarried women aged 15-19 and 20-24 years, respectively. ${ }^{16}$ These estimates are lower compared with the respective estimates $(43.7 \%$ and $53.4 \%$ ) from the $2014^{19}$ and $2008^{20}(66.6 \%$ and $74.0 \%)$ Ghana demographic and health surveys. Meeting adolescents' contraceptive need was pertinent in achieving the Ghana Family Planning 2020 goal of expanding the use of modern contraception from 1.46 million in 2015 to 1.93 million in 2020, and increasing contraceptive use among sexually active unmarried adolescents by $2020 .{ }^{21}$ It is also a requirement to meet Sustainable Development Goal 3.7 on sexual and reproductive health, which targets among others that by 2030, there should be universal access to family planning or contraceptive use for all ages. $^{22}$

Most research on contraception use are conducted among all women of reproductive age (15-49 years), without detailed stratified analysis by age. ${ }^{23}$ Several studies in Ghana have looked at contraceptive use among adolescent and young women. ${ }^{7825-27}$ However, very few studies on adolescent contraceptive use have explored determinants of contraceptive use, making use of nationally representative data. ${ }^{28} 29$ Also, studies that used nationally representative data mostly used data from the past Ghana demographic and health surveys, ${ }^{28-30}$ of which the latest one is already more than half a decade old. ${ }^{19}$ This study is a secondary analysis of the 2017 GMHS, which includes nationally representative data on contraception use. With a focus on sexually active unmarried adolescents (15-19 years) and young women (20-24 years), we assessed the knowledge and prevalence of contraceptive use, and determinants of contraceptive use in Ghana. In addition, we explored the age differentials in knowledge and use of the different contraceptive methods.

\section{METHODS}

\section{Data source and data description}

Data from the 2017 GMHS $^{16}$ were used in this study. The 2017 GMHS was the second maternal health survey, following the first survey conducted in $2007 .{ }^{17}$ The survey which was cross-sectional in design and nationally representative collected household and individual-level data on maternal health and maternal mortality in Ghana.

The sample for this survey was stratified and selected in two stages. The 10 administrative regions of Ghana were grouped into rural and urban, resulting in 20 sampling strata. The first stage involved probability proportional sampling of a total of 900 enumeration areas (clusters) from all the regions, with 466 clusters from the urban areas and 434 from rural areas. In the second stage, 30 households were randomly sampled from each cluster, resulting in a total sample size of 27000 households. The 2010 Population and Housing Census of Ghana, ${ }^{31}$ with enumeration area covering an average of 161 households, was used as the sampling frame for the 2017 GMHS.

The survey sampled 27001 households, of which 26500 were occupied. Out of the 26500 occupied households, 26324 (99\%) were interviewed. From the 26324 interviewed households, 25304 women between 15 and 49 years were eligible to participate in the survey, among which 25062 (99\%) were successfully interviewed. All study respondents provided informed consent for their participation in the survey. Additional details of the survey design and methodology can be found in the survey report. ${ }^{16}$

Of the 25062 individual respondents, 15052 (60.1\%) were married or living together with a man. Among the remaining 10010 unmarried respondents, 6614 (66.1\%) were between 15 and 24 years. Unmarried respondents are those who were single, divorced, widowed or separated. Of the 6614 unmarried respondents between 15 and 24 years, $809(12.2 \%)$ were sexually active (had sexual intercourse within 30 days of the survey). Details of the data description are shown in figure 1. Given our interest in contraceptive use among sexually active unmarried adolescents and young women aged 15-24 years, data from the subset of 809 respondents were included in our data analysis.

\section{Study variables}

The variables used in the analysis include data on knowledge and use of contraceptive methods, background characteristics of respondents such as age, level of education, place of residence, household-level wealth quintile and region of residence. Also, data on age at first sex, history 


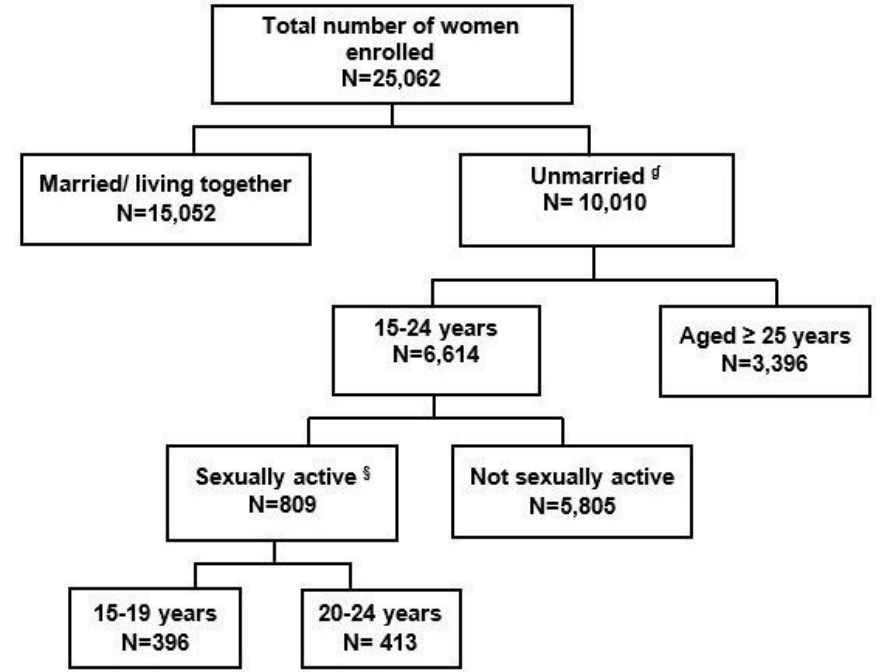

Figure 1 Description of study data. gWomen are not currently married or in a consensual union (single, divorced, widowed or separated). §Women who had sexual intercourse within 30 days of the survey.

of pregnancy, abortion and childbirth were included. Table 1 provides a detailed description of the study variables. Contraceptive knowledge was defined as having heard of any contraceptive method (either modern or traditional methods). Contraceptive use was assessed through an affirmative response to the question 'Are you or your partner currently doing something or using any method to delay or avoid getting pregnant?' This includes the use of any modern or traditional contraceptive method. Modern methods comprised female sterilisation, male sterilisation, intrauterine devices (IUD), injectables, implants, pills, male condoms, female condoms, emergency contraception and lactational amenorrhoea method. Traditional methods include the rhythm and withdrawal method. Even though data on contraceptive use were retrospectively assessed, by including sexually active respondents (those who had sexual intercourse within 30 days of the survey), recall bias was significantly minimised.

\section{Patient and public involvement}

No patient involved. Key stakeholder meetings will be organised to share the findings of this study with Ghana Health Service who are in charge of healthcare delivery in the country.

\section{Statistical analysis}

To account for the non-proportional allocation of the sample to the different regions, sampling weights were used to obtain national/regional representation of the survey results. Given the two-stage stratified cluster sampling approach used in the survey, sampling weights were calculated separately for each sampling stage and each cluster based on sampling probabilities. Details of the design and sampling weights can be found in the survey report. ${ }^{16}$ Results were left blank if they are based on less than 15 unweighted respondents. $\chi^{2}$ tests were
Table 1 Description of variables used in the study

\begin{tabular}{ll}
\hline Variable & Description/definition \\
\hline Contraceptive & Respondents who have heard of any \\
knowledge & contraceptive method, both modern
\end{tabular}
knowledge contraceptive method, both modern and traditional (yes; no)

Contraceptive Respondents who were doing something or use using any method to delay or avoid getting pregnant (yes; no)

Age $\quad \begin{aligned} & \text { Age of respondent (15-19 years } \\ & \text { (adolescents); 20-24 years (young women) }\end{aligned}$

Level of Respondents' highest level of education education (no education; primary education; middle/ junior secondary/high school; secondary/ senior secondary/ high school; more than secondary)

$\begin{array}{ll}\begin{array}{l}\text { Place of } \\ \text { residence }\end{array} & \begin{array}{l}\text { Respondents' place of residence (urban; } \\ \text { rural) }\end{array}\end{array}$

Household These are scores based on the no and level wealth kinds of consumer goods owned by a quintile respondents household, ranging from a television to a bicycle or car, and housing characteristics such as source of drinking water, toilet facilities and flooring materials. ${ }^{16}$ (Lowest; second; middle; fourth; highest)

$\begin{array}{ll}\text { Region of } & \text { Respondents' region of residence from } \\ \text { residence } & \text { the } 10 \text { administrative regions in Ghana } \\ & \text { (Western; Central; Greater Accra; Volta; } \\ & \text { Eastern; Ashant; } \\ & \text { Brong Ahafo; Northern; Upper East; Upper } \\ & \text { West) }\end{array}$

Age at first sex Age at which respondent first had sexual intercourse ( $\leq 14$ years, $\geq 15$ years)

$\begin{array}{ll}\text { Ever been } & \text { History of past pregnancy/pregnancies (yes; } \\ \text { pregnant } & \text { no) }\end{array}$

Abortion in the History of abortion in the 5 years before the past 5 years survey (yes; no)

Ever given History of child birth (yes; no)

birth

used to assess the association between use of contraceptive methods, knowledge of contraceptive methods and respondents' age (15-19 years vs 20-24 years).

Weighted univariate and multivariate logistic regression were used to study the association between background and obstetric characteristics of respondents and contraceptive use. With an interest in all the selected sociodemographic and obstetric variables, we included all the variables in a multivariate logistic regression model regardless of their statistical significance in the univariate analysis. However, abortion in the past 5 years and history of child birth were excluded from the multivariate model due to collinearity with history of past pregnancy.

In the multivariate analysis, significance was established at a level of $5 \%$. Data analysis was performed using STATA V.15.0. 


\section{RESULTS}

\section{Characteristics of study participants}

A total of 809 sexually active unmarried adolescents and young women aged 15-24 years were included in this secondary analysis. Respondents were almost equally distributed between the two age groups (49\% and 51\% for the 15-19 years and 20-24 years, respectively). The background and obstetric characteristics of the respondents are presented in table 2 . The majority of the respondents had middle/junior secondary school/junior high school education. Among all the respondents, $44 \%$ had ever been pregnant, $23 \%$ have ever had an abortion and $26 \%$ had ever given birth.

\section{Contraceptive use}

The prevalence of contraceptive use is presented in table 3 by the type of method used. The contraceptive prevalence rate (CPR) among adolescents and young women aged 15-24 years was 43\%, with 34\% using modern methods and 9\% using traditional methods. Compared with respondents aged 15-19 years, CPR was significantly higher among those aged 20-24 years ( $49 \%$ vs $36 \%, \mathrm{p}=0.002$ ). The use of modern contraceptive methods was significantly higher among respondents between 20 and 24 years compared with those between 15 and 19 years $(39 \%$ vs $27 \%, \mathrm{p}=0.005)$. Although only $0.5 \%$ of the respondents used IUD, compared with respondents between 20 and 24 years, significantly more respondents between 15 and 19 years used this method $(0.1 \%$ vs $1.0 \%, \mathrm{p}=0.008$ ).

\section{Knowledge of contraceptive methods}

Knowledge on the different contraceptive methods is presented in table 3 , distinguished by the type of method (modern or traditional) and age of respondents. The most commonly known contraceptive method was the male condom $(99 \%)$, while male sterilisation was the least known method (33\%). Knowledge of at least one modern and traditional contractive method was $99.8 \%$ and $95.0 \%$, respectively. Compared with respondents between 15 and 19 years, knowledge on the use of male sterilisation $(\mathrm{p}=0.020)$, IUD $(\mathrm{p}=0.029)$, implants $(\mathrm{p}<0.001)$, pill $(p=0.007)$, emergency contraception $(p=0.001)$, lactational amenorrhoea $(\mathrm{p}=0.006)$, rhythm $(\mathrm{p}=0.002)$ and withdrawal method $(\mathrm{p}<0.001)$ was significantly higher among those between 20 and 24 years.

\section{Contraceptive use by demographic and obstetric characteristics of respondents}

CPR by background characteristics of respondents is presented in table 4, stratified by age. Among all respondents, CPR differed by level of education $(\mathrm{p}=0.032)$ and region of residence $(p=0.048)$. Also, overall, CPR was higher among those who had ever been pregnant $(52.5 \%$ vs $35.1 \%, \mathrm{p}<0.001)$, those who have had an abortion in the last 5 years $(54.4 \%$ vs $39.9 \%, \mathrm{p}=0.006)$ and those who had ever given birth $(51.2 \%$ vs $39.8 \%, \mathrm{p}=0.025)$.
Table 2 Background characteristics of study participants $(\mathrm{N}=809)$

\begin{tabular}{|c|c|c|c|c|}
\hline & $\begin{array}{l}\text { Weighted } \\
\mathbf{N}\end{array}$ & $\begin{array}{l}\text { Overall } \\
\text { (15-24 } \\
\text { years) }\end{array}$ & $\begin{array}{l}15-19 \\
\text { years }\end{array}$ & $\begin{array}{l}20-24 \\
\text { years }\end{array}$ \\
\hline \multicolumn{5}{|l|}{ Education } \\
\hline No education & 39 & 4.8 & 5.5 & 4.2 \\
\hline Primary & 115 & 14.3 & 18.2 & 10.9 \\
\hline Middle/JSS/JHS & 369 & 45.6 & 53.1 & 39.0 \\
\hline Secondary/SSS/SHS & 259 & 32.0 & 22.9 & 39.7 \\
\hline More than secondary & 27 & 3.4 & 0.2 & 6.1 \\
\hline \multicolumn{5}{|l|}{ Place of residence } \\
\hline Urban & 444 & 54.9 & 46.7 & 62.0 \\
\hline Rural & 365 & 45.1 & 53.3 & 38.0 \\
\hline \multicolumn{5}{|l|}{ Household wealth quintile } \\
\hline Lowest & 124 & 15.4 & 23.3 & 8.5 \\
\hline Second & 195 & 24.1 & 23.4 & 24.6 \\
\hline Middle & 201 & 24.9 & 23.9 & 25.7 \\
\hline Fourth & 188 & 23.2 & 21.6 & 24.6 \\
\hline Highest & 101 & 12.5 & 7.8 & 16.5 \\
\hline
\end{tabular}

Region

\begin{tabular}{|rrrrr}
\hline Western & 138 & 17.1 & 14.1 & 19.7 \\
\hline Central & 57 & 7.1 & 7.5 & 6.7 \\
\hline Greater Accra & 82 & 10.2 & 9.2 & 11.0 \\
\hline Volta & 96 & 11.8 & 14.1 & 9.8 \\
\hline Eastern & 85 & 10.6 & 11.0 & 10.1 \\
\hline Ashanti & 176 & 21.8 & 18.1 & 24.9 \\
\hline Brong Ahafo & 92 & 11.3 & 12.2 & 10.5 \\
\hline Northern & 52 & 6.4 & 9.7 & 3.5 \\
\hline Upper East & 12 & 1.4 & 1.6 & 1.3 \\
\hline Upper West & 19 & 2.4 & 2.4 & 2.4 \\
\hline Age at first sex & & & & \\
\hline$\leq 14$ years & 171 & 21.1 & 31.4 & 12.2 \\
\hline$\geq 15$ years & 638 & 78.9 & 68.6 & 87.8 \\
\hline Ever been pregnant & & & & \\
\hline No & 452 & 55.9 & 70.7 & 43.0 \\
\hline Yes & 357 & 44.1 & 29.3 & 57.0 \\
\hline Ever had an abortion & & & & \\
\hline No & 627 & 77.5 & 87.2 & 69.1 \\
\hline Yes & 182 & 22.5 & 12.8 & 30.9 \\
\hline Ever given birth & & & & \\
\hline No & 600 & 74.1 & 80.8 & 68.3 \\
\hline Yes & 209 & 25.9 & 19.2 & 31.7 \\
\hline
\end{tabular}

JHS, junior high school; JSS, junior secondary school; SHS, senior high school; SSS, senior secondary school.

Among respondent between 15 and 19 years, CPR was higher among those who had ever been pregnant $(49.0 \%$ vs $30.0 \%, \mathrm{p}=0.006$ ) and among those who had ever given 
Table 3 Knowledge and use of contraceptives among sexually active unmarried adolescent and young women aged 15-24

\begin{tabular}{|c|c|c|c|c|c|c|c|c|}
\hline \multirow[b]{3}{*}{ Contraceptive method } & \multicolumn{4}{|c|}{ Contraceptive use } & \multicolumn{4}{|c|}{ Contraceptive knowledge } \\
\hline & \multicolumn{3}{|c|}{ Age groups } & \multirow[b]{2}{*}{$P$ value } & \multicolumn{3}{|c|}{ Age groups } & \multirow[b]{2}{*}{$\mathbf{P}$ value } \\
\hline & $15-24$ & $15-19$ & $20-24$ & & $15-24$ & $15-19$ & $20-24$ & \\
\hline Female sterilisation & 0.0 & 0.0 & 0.0 & - & 76.5 & 73.1 & 79.4 & 0.096 \\
\hline Male sterilisation & 0.3 & 0.6 & 0.0 & 0.137 & 33.0 & 27.6 & 37.7 & 0.020 \\
\hline Injectables & 6.6 & 4.8 & 8.1 & 0.112 & 93.1 & 91.1 & 94.9 & 0.084 \\
\hline Implants & 6.5 & 4.7 & 8.0 & 0.128 & 91.2 & 86.8 & 95.1 & $<0.001$ \\
\hline Pill & 5.5 & 4.6 & 6.3 & 0.411 & 91.3 & 88.1 & 94.0 & 0.007 \\
\hline Male condoms & 7.2 & 6.7 & 7.6 & 0.665 & 99.2 & 99.0 & 99.5 & 0.436 \\
\hline Female condoms & 0.0 & 0.0 & 0.0 & - & 88.4 & 86.5 & 90.2 & 0.168 \\
\hline Any modern method & 33.7 & 27.2 & 39.3 & 0.005 & 99.8 & 99.5 & 100.0 & 0.049 \\
\hline \multicolumn{9}{|l|}{ Traditional methods } \\
\hline Rhythm & 6.2 & 4.8 & 7.3 & 0.279 & 83.9 & 78.7 & 88.4 & 0.002 \\
\hline Withdrawal & 2.9 & 3.5 & 2.4 & 0.344 & 88.5 & 83.7 & 92.7 & $<0.001$ \\
\hline Any traditional method & 9.1 & 8.4 & 9.8 & 0.591 & 95.0 & 92.1 & 97.5 & 0.002 \\
\hline $\begin{array}{l}\text { Any contraceptive method (both modern } \\
\text { and traditional methods) }\end{array}$ & 42.8 & 35.6 & 49.0 & 0.002 & 99.8 & 99.5 & 100.0 & 0.049 \\
\hline
\end{tabular}

$P$ values $<0.05$ are highlighted in bold and italicised text.

birth $(53.0 \%$ vs $31.5 \%, \mathrm{p}=0.013)$. CPR also differed by respondents' region of residence, with the highest prevalence in the Western region and lowest prevalence in the Greater Accra region $(p=0.024)$. Among respondents between 20 and 24 years, CPR was significantly higher among those who had ever been pregnant compared with those who had never been pregnant $(54.1 \%$ vs $42.3 \%$, $\mathrm{p}=0.040)$.

\section{Determinants of contraceptive use}

The results for the association between the demographic and obstetric characteristics of respondents and contraceptive use are presented in table 5 . At a $5 \%$ significant level, age $(\mathrm{p}=0.002)$, ever been pregnant $(\mathrm{p}<0.001)$, abortion in the past 5 years $(p=0.007)$ and ever given birth $(\mathrm{p}=0.025)$ were independently associated with contraceptive use. However, education $(p=0.072)$, place of residence $(\mathrm{p}=0.702)$, household wealth quintile $(\mathrm{p}=0.836)$ and age at first sex $(p=0.924)$ were not independently associated with contraceptive use.

Due to collinearity with history of past pregnancy, abortion in the past 5 years, and history of child birth were excluded from the adjusted model. In the adjusted analysis, education and pregnancy history were significantly associated with contraceptive use. Respondents with secondary level education were more likely to use contraceptives compared with those with primary education (OR 2.43, 95\% CI 1.31 to $4.49, \mathrm{p}=0.017)$. Also, respondents who had ever been pregnant were more likely to use contraceptives compared with those who had never been pregnant (OR 2.13, 95\% CI 1.48 to 3.06, $\mathrm{p}<0.001$ ).

\section{DISCUSSION}

This study used data from the 2017 GMHS $^{16}$ to present nationally representative estimates on the prevalence of contraceptive knowledge and use, and to assess the determinants of contraceptive use among sexually active unmarried adolescent girls (15-19 years) and young women (20-24 years) in Ghana. Similar to the results of other studies on contraceptive knowledge in Ghana, ${ }^{25} 2732$ we found knowledge of contraceptive methods to be almost universal, with a prevalence of $99.8 \%$ and $95.0 \%$ for at least one modern and at least one traditional method, respectively. The CPR was $43 \%$, with $34 \%$ use of modern methods and $9 \%$ use of traditional methods. Compared with usage among the entire population of adolescents $(9.8 \%)$ and young women $(28.6 \%)$ in Ghana, ${ }^{16}$ contraceptive use is higher among sexually active unmarried adolescent girls (15-19 years; 35.6\%) and young women (20-24 years; $49.0 \%$ ).

The choice of contraceptives by sexually active unmarried adolescents and young women in Ghana is different from the choice of contraceptives among all women of reproductive age. For modern contraceptives, among 
Table 4 Contraceptive use by background characteristics of respondents

\begin{tabular}{|c|c|c|c|c|c|c|c|}
\hline \multirow{2}{*}{ Variable } & \multirow[b]{2}{*}{$\mathbf{N}$} & \multicolumn{2}{|c|}{ Overall (15-24 years) } & \multicolumn{2}{|l|}{$15-19$ years } & \multicolumn{2}{|l|}{$20-24$ years } \\
\hline & & $\%(95 \% \mathrm{Cl})$ & $P$ value & $\%(95 \% \mathrm{Cl})$ & $P$ value & $\%(95 \% \mathrm{Cl})$ & $P$ value \\
\hline \multicolumn{8}{|l|}{ Education } \\
\hline No education & 39 & 40.8 (23.7 to 60.5$)$ & 0.032 & $24.7(7.2$ to 57.9$)$ & 0.083 & 59.1 (34.9 to 79.6$)$ & 0.429 \\
\hline Primary & 115 & 35.7 (25.7 to 47.1$)$ & & 27.1 (16.4 to 41.3 ) & & 48.1 (31.2 to 65.4$)$ & \\
\hline Middle/JSS/JHS & 369 & 38.0 (31.7 to 44.7$)$ & & 33.3 (25.9 to 41.5$)$ & & 43.6 (33.6 to 54.1$)$ & \\
\hline Secondary/SSS/SHS & 259 & 53.1 (44.7 to 61.4$)$ & & 49.7 (36.2 to 63.2) & & 54.9 (45.3 to 64.1$)$ & \\
\hline More than secondary & 27 & 42.2 (23.2 to 63.9$)$ & & - & & 40.5 (21.5 to 62.8$)$ & \\
\hline \multicolumn{8}{|l|}{ Place of residence } \\
\hline Urban & 444 & 42.0 (35.7 to 48.6$)$ & 0.702 & 33.9 (25.1 to 44.1$)$ & 0.630 & 47.3 (39.9 to 54.8 ) & 0.439 \\
\hline Rural & 365 & 43.7 (38.0 to 49.6$)$ & & 37.0 (29.2 to 45.7$)$ & & 51.8 (43.2 to 60.4$)$ & \\
\hline \multicolumn{8}{|l|}{ Household wealth quintile } \\
\hline Lowest & 124 & 41.1 (30.9 to 52.0) & 0.838 & 32.1 (20.7 to 46.1 ) & 0.807 & 62.2 (43.3 to 77.9$)$ & 0.504 \\
\hline Second & 195 & 40.4 (30.7 to 50.9$)$ & & 39.1 (27.6 to 52.0$)$ & & 41.4 (29.8 to 54.1$)$ & \\
\hline Middle & 201 & 46.1 (37.9 to 54.5$)$ & & 39.6 (28.2 to 52.3$)$ & & $51.3(40.0$ to 62.6$)$ & \\
\hline Fourth & 188 & 40.9 (31.9 to 50.5$)$ & & 30.5 (19.5 to 44.2$)$ & & 48.8 (36.7 to 61.0$)$ & \\
\hline Highest & 101 & 46.5 (35.1 to 58.2$)$ & & 37.2 (17.8 to 61.9$)$ & & 50.2 (36.3 to 64.1$)$ & \\
\hline \multicolumn{8}{|l|}{ Region } \\
\hline Western & 138 & 52.0 (41.5 to 62.3 ) & 0.048 & 53.0 (36.5 to 68.9$)$ & 0.024 & 51.4 (39.9 to 62.7$)$ & 0.908 \\
\hline Central & 57 & 40.5 (27.8 to 54.7$)$ & & 29.2 (12.5 to 54.2$)$ & & 51.5 (30.3 to 72.2$)$ & \\
\hline Greater Accra & 82 & 27.6 (16.7 to 42.1$)$ & & $12.9(4.6$ to 31.2$)$ & & 38.2 (21.8 to 57.8$)$ & \\
\hline Volta & 96 & 43.3 (29.9 to 57.6$)$ & & 41.8 (23.4 to 62.9$)$ & & 45.0 (32.4 to 58.2$)$ & \\
\hline Eastern & 85 & 35.3 (24.3 to 48.1$)$ & & 23.9 (11.6 to 43.0$)$ & & 46.1 (30.1 to 62.9) & \\
\hline Ashanti & 176 & 50.7 (39.4 to 62.0) & & 46.6 (30.4 to 63.7$)$ & & 53.3 (39.8 to 66.3 ) & \\
\hline Brong Ahafo & 92 & 43.9 (33.4 to 55.1$)$ & & 37.2 (23.2 to 53.6$)$ & & 50.8 (33.9 to 67.5$)$ & \\
\hline Northern & 52 & 30.6 (22.1 to 40.7$)$ & & $23.3(15.1$ to 34.1$)$ & & 48.3 (32.6 to 64.3 ) & \\
\hline Upper East & 12 & 35.3 (20.5 to 53.6$)$ & & 14.8 (3.6 to 44.3 ) & & 55.9 (33.7 to 75.9$)$ & \\
\hline Upper West & 19 & 38.1 (24.8 to 53.4$)$ & & 28.6 (16.4 to 45.0$)$ & & 46.4 (27.8 to 66.1$)$ & \\
\hline \multicolumn{8}{|l|}{ Age at first sex } \\
\hline$\leq 14$ years & 171 & $42.4(32.6$ to 52.7$)$ & 0.924 & 34.2 (23.7 to 46.5$)$ & 0.770 & 60.6 (43.9 to 75.1$)$ & 0.135 \\
\hline$\geq 15$ years & 638 & 42.9 (38.2 to 47.8$)$ & & $36.2(29.1$ to 44.0$)$ & & 47.4 (41.6 to 53.3$)$ & \\
\hline \multicolumn{8}{|l|}{ Ever been pregnant } \\
\hline No & 452 & 35.1 (29.9 to 40.7) & $<0.001$ & 30.0 (23.9 to 37.1$)$ & 0.006 & 42.3 (34.0 to 50.9$)$ & 0.040 \\
\hline Yes & 357 & 52.5 (46.0 to 59.0$)$ & & 49.0 (36.9 to 61.2$)$ & & 54.1 (46.7 to 61.4 ) & \\
\hline \multicolumn{8}{|c|}{ Abortion in the last 5 years } \\
\hline No & 646 & $39.9(35.1$ to 44.8$)$ & 0.006 & 34.0 (27.7 to 41.1$)$ & 0.137 & 46.1 (39.7 to 52.6) & 0.086 \\
\hline Yes & 163 & 54.4 (44.9 to 63.6$)$ & & 47.9 (31.1 to 65.2$)$ & & 56.7 (46.0 to 66.7$)$ & \\
\hline \multicolumn{8}{|l|}{ Ever given birth } \\
\hline No & 600 & 39.8 (35.0 to 44.9$)$ & 0.025 & 31.5 (25.5 to 38.2$)$ & 0.013 & 48.4 (41.6 to 55.3$)$ & 0.763 \\
\hline Yes & 209 & 51.2 (42.5 to 59.8$)$ & & 53.0 (37.0 to 68.4$)$ & & 50.3 (40.5 to 60.0$)$ & \\
\hline
\end{tabular}

$P$ values $<0.05$ are highlighted in bold and italicised text.

JHS, junior high school; JSS, junior secondary school; SHS, senior high school; SSS, senior secondary school.

all women of reproductive age, injectables $(6.0 \%)$ and implants $(5.3 \%)$ are the most used methods. ${ }^{16}$ However, among sexually active unmarried adolescents and young women, emergency contraception $(7.2 \%)$ and male condom $(7.2 \%)$ are the most used modern contraceptive methods. Emergency contraception appears to be a popular contraceptive method among young women in Ghana. Among respondents between 20 and 24 years, 
Table 5 Factors associated with contraceptive use

\begin{tabular}{|c|c|c|c|c|}
\hline \multirow[b]{2}{*}{ Variable } & \multicolumn{2}{|l|}{ Univariate analysis } & \multicolumn{2}{|c|}{ Multivariate analysis } \\
\hline & OR (95\% Cl) & Overall $\mathbf{P}$ value & OR $(95 \% \mathrm{Cl})$ & Overall $\mathbf{P}$ value \\
\hline \multicolumn{5}{|l|}{ Age } \\
\hline $20-24$ & 1.74 (1.23 to 2.46$)$ & & 1.31 (0.90 to 1.92) & \\
\hline \multicolumn{5}{|l|}{ Education } \\
\hline Primary & 1 & & 1 & \\
\hline Middle/JSS/JHS & 1.11 (0.64 to 1.92) & & 1.14 (0.65 to 1.99$)$ & \\
\hline Secondary/SSS/SHS & 2.05 (1.11 to 3.76$)$ & & 2.43 (1.31 to 4.49$)$ & \\
\hline More than secondary & 1.32 (0.49 to 3.56$)$ & & 1.72 (0.57 to 5.22$)$ & \\
\hline \multicolumn{5}{|l|}{ Place of residence } \\
\hline Lowest & 1 & 0.836 & 1 & 0.816 \\
\hline Second & 0.97 (0.54 to 1.74$)$ & & 0.83 (0.46 to 1.53$)$ & \\
\hline Middle & 1.23 (0.70 to 2.16$)$ & & $0.98(0.55$ to 1.74$)$ & \\
\hline Fourth & 0.99 (0.56 to 1.77$)$ & & $0.75(0.40$ to 1.39$)$ & \\
\hline Highest & 1.25 (0.65 to 2.38$)$ & & 0.93 (0.45 to 1.94$)$ & \\
\hline \multicolumn{5}{|l|}{ Age at first sex } \\
\hline$\leq 14$ years & 1 & 0.924 & 1 & 0.814 \\
\hline$\geq 15$ years & $1.02(0.65$ to 1.61$)$ & & 0.94 (0.59 to 1.52$)$ & \\
\hline \multicolumn{5}{|l|}{ Ever been pregnant } \\
\hline \multicolumn{5}{|l|}{ Ever given birth } \\
\hline No & 1 & 0.025 & & \\
\hline Yes & 1.58 (1.06 to 2.37 ) & & & \\
\hline
\end{tabular}

$P$ values $<0.05$ are highlighted in bold and italicised text.

JHS, junior high school; JSS, junior secondary school; SHS, senior high school; SSS, senior secondary school.

emergency contraception was the most used modern contraceptive method $(9.3 \%)$. Other studies in Ghana have also reported high emergency contraception use among adolescents and young women. ${ }^{33}$ A qualitative study on emergency contraception use among young unmarried women in Ghana's capital found the method to be the most preferred and most used. ${ }^{33}$ In a study by Grindlay et $a l^{34}$ next to the use of male condom, emergency contraceptives was the second most popular modern contraceptive method used by young female respondents between 18 and 24 years.

In our analysis, we found age, history of pregnancy, abortion in the past 5 years and history of child birth to be independently associated with contraceptive use. However, in an adjusted analysis, contraceptive use was significantly higher among respondents with secondary level education, and in those with a history of pregnancy. Other studies in Ghana ${ }^{28}$ and other parts of Africa ${ }^{356}$ have also reported high contraceptive use among respondents with secondary education. The high use of contraceptives among respondents with secondary education compared with those with primary education can be attributed to how informed respondents with higher education are about the benefits of contraceptive use. Education also empowers women to make better decisions concerning their reproductive health. Participants who have been pregnant in the past may have already experienced the consequences of non-use of contraceptives and may have learnt their lessons. Also, in Ghana, education on contraceptive use is part of the services provided to pregnant 
women during antenatal care attendance. As such, respondents who have ever been pregnant may have been educated on the importance of contraceptive use and may also know where and how contraceptives could be obtained. Other studies in Ghana on adolescent sexual and reproductive health have shown that most young women who get pregnant wished they were educated on contraceptive use before the pregnancy. ${ }^{78}$ This emphasises the need to make family planning or contraceptive use available for all ages.

It is worthy to point the significant gap observed between knowledge and use of contraceptives, which is consistent with the results of other studies. ${ }^{25} 273237$ This may be due to several factors including knowledge of where and how family planning methods could be obtained. Another factor contributing to the gap between knowledge and use of contraceptives is the myth surrounding the use of various methods and the female sex..$^{25}$ Owing to several factors including societal norms and stigmatisation, it is difficult in the Ghanaian setting for a young female to easily have access to contraceptives. ${ }^{38}$ It has also been reported that male sexual partners often may not accept a condom from their female counterparts. ${ }^{38} 39$ Hence, females may be aware of various contraceptive methods, they are however limited in acquiring them and initiating their use.

Several other factors have been attributed to the nonuse of contraceptives among sexually active unmarried young women. This includes lack of education on how to use contraceptives and their potential side effects. ${ }^{40}$ Studies have reported that some women are less motivated to use contraceptives because of their perception of the risk and side effects of some of the methods. ${ }^{10}{ }^{4041}$ Recent studies in central Ghana revealed that sexually active adolescents seeking contraceptives are stigmatised and perceived as bad or spoilt kids. ${ }^{725}$ Another barrier to contraceptive use is judgemental healthcare providers, who may deny adolescents contraceptive services if they feel adolescents 'are not old enough' or are unmarried. Adolescents are thus shy to access contraceptives. ${ }^{7}$

Non-use of contraceptive is often associated with UP, which has deleterious consequences on young females, including dropping out of school, ${ }^{42}$ which result in truncation of future development. ${ }^{43-45}$ UP often end in induced abortion, ${ }^{14}$ with a significant number being unsafe abortions. ${ }^{15} 17$ Unsafe abortion is widespread among adolescents in Ghana, and it contributes significantly to the burden of morbidity and mortality in the country ${ }^{46}$; about $35 \%$ of all women who die as a result of unsafe abortion in Ghana are adolescents. ${ }^{47}$ To this end, promoting contraceptive use among adolescents and young girls, as well as ensuring the availability of quality postabortion contraception is undoubtedly very important. Apart from the fact that promoting contraceptive use contributes to achieving international targets, ${ }^{21}{ }^{22}$ it also prevents UPs, unsafe abortions and abortion-related complications. In recognising the need to promote and increase contraceptive use in Ghana, the government of Ghana through the 2012 National Health Insurance Act authorised that family planning should be free under its national health insurance scheme. ${ }^{48}$ However, to date, this has still not been implemented. In the meantime, the government has increased its financial contribution towards the procurement of family planning commodities, and currently, purchases about $25 \%$ of all family planning commodities in the country. Also, more health service providers have been trained in Adolescent and Youth-friendly Health Services. ${ }^{21}$

Given that a higher percentage of sexually active unmarried adolescents and young women in Ghana do not use contraceptives, appropriate interventions should be put in place to promote contraceptive use among this population to mitigate the deleterious consequences associated with adolescent pregnancy. Pertinent among these interventions is for relevant key stakeholders like the Family Health Division of the Ghana Health Service to embark on public education regarding the importance of contraceptive use, and making contraceptives accessible for people who need them. Evidence suggests that the use of adolescentfriendly reproductive health facilities improves usage of several health services including contraceptives. ${ }^{450}$ Owing to the stigma associated with contraceptive use among adolescents and young women, we advocate for setting up confidential, friendly and non-judgemental adolescent reproductive health centres in the community and the different levels of educational institutions in Ghana. Literature highlights a very important role of commercial drug sellers as far as adolescents and young women contraceptive sourcing is concerned. ${ }^{4}$ Given the barriers adolescents and young women encounter in seeking contraceptive services, community-based drug outlets and pharmacies can complement the adolescent-friendly centres. These facilities are more accessible, provide faster services, have longer opening hours and are confidential in providing adolescents and young women with contraceptive services. ${ }^{51}$ The stigma attached to adolescents, most especially late teenagers who patronise contraceptives services should be addressed by intensifying health education, particularly at the community level. In this study, more than $70 \%$ of the respondents owned a mobile phone. In light of this high rate of mobile phone use, contraceptive use interventions for young women could be pursued through mobile phones.

It should be emphasised that the use of nationally representative data can be of great importance in identifying several issues of public health importance. This study used data from the GMHS to assess contraceptive use among a population that is often underrepresented in sexual and reproductive health studies. To this end, the findings of this study can only be generalised to sexually active unmarried adolescent girls and young women aged 15-24 years in Ghana.

\section{CONCLUSION}

Knowledge of contraceptive methods is almost universal among sexually active unmarried adolescent girls and 
young women in Ghana. However, this does not reflect on the use of these methods. To address the gap in contraceptive use among young women, the Ghana Health Service and other relevant stakeholders should ensure that contraceptive services are available and easily accessible in Ghana. Also, outreach contraceptives services in Ghana should be intensified and expanded to places where adolescents and young women can easily access the services without fear of stigma by society. We advocate for the setting up of confidential, friendly and nonjudgemental adolescent reproductive health centres in the community and different levels of the educational institutions in Ghana. More gender-transformative approaches, including thoughtful collaborations with other sectors (eg, education, local government), should be explored.

\section{Author affiliations}

${ }^{1}$ Global Statistical Institute, Techiman, Ghana

${ }^{2}$ Research and Development Division, Ghana Health Service, Accra, Ghana

${ }^{3}$ Sunyani Municipal Health Directorate, Ghana Health Service, Sunyani, Ghana

${ }^{4}$ Department of Global and International Health, School of Public Health, College of Health Sciences, Kwame Nkrumah University of Science and Technology, Kumasi, Ghana

${ }^{5}$ Kintampo Health Research Centre, Kintampo, Ghana

Acknowledgements The authors are grateful to the DHS program for providing them access to the 2017 Ghana Maternal Health Survey database. We are also grateful to the survey participants.

Contributors $\mathrm{FBO}, \mathrm{DDL}$ and KAA-N conceived the idea and conceptualised the study. FBO conducted the data analysis and wrote the first draft. KA-W, AAA and SA contributed significantly to the statistical analyses. SA-A and SYA provided critical contributions to the discussion of the findings of the study. All authors contributed to the study design and review of the manuscript.

Funding The authors have not declared a specific grant for this research from any funding agency in the public, commercial or not-for-profit sectors.

Competing interests None declared.

Patient and public involvement Patients and/or the public were not involved in the design, or conduct, or reporting, or dissemination plans of this research.

Patient consent for publication Not required.

Ethics approval This study is based on publicly available DHS data. FBO was granted access to the data by the Demographic and Health Surveys (DHS) Programme, Rockville, Maryland, USA.

Provenance and peer review Not commissioned; externally peer reviewed.

Data availability statement Data may be obtained from a third party and are not publicly available. This study is a secondary data analysis of the 2017 Ghana Maternal Health Survey. The data set is not publicly available but can be requested from the DHS programme on reasonable request.

Open access This is an open access article distributed in accordance with the Creative Commons Attribution Non Commercial (CC BY-NC 4.0) license, which permits others to distribute, remix, adapt, build upon this work non-commercially, and license their derivative works on different terms, provided the original work is properly cited, appropriate credit is given, any changes made indicated, and the use is non-commercial. See: http://creativecommons.org/licenses/by-nc/4.0/.

\section{ORCID iD}

Felix Boakye Oppong http://orcid.org/0000-0002-3146-9958

\section{REFERENCES}

1 Ali M, Farron M, Ouedraogo L, et al. Research gaps and emerging priorities in sexual and reproductive health in Africa and the eastern Mediterranean regions. Reprod Health 2018;15:39.
2 UNICEF. Child marriage: latest trends and future prospects. New York: UNICEF, 2018.

3 United Nations (UN). Adolescent fertility since the International Conference on population and development (ICPD) in Cairo, 2013.

4 Radovich E, Dennis ML, Wong KLM, et al. Who meets the contraceptive needs of young women in sub-Saharan Africa? $J$ Adolesc Health 2018;62:273-80.

5 Ali MM, Cleland J. Long term trends in behaviour to protect against adverse reproductive and sexual health outcomes among young single African women. Reprod Health 2018;15:136.

6 Atuyambe LM, Kibira SPS, Bukenya J, et al. Understanding sexual and reproductive health needs of adolescents: evidence from a formative evaluation in Wakiso district, Uganda. Reprod Health 2015;12:1-10.

7 Enuameh Y, Boamah E, Nettey O. Improving family planning service delivery to adolescents in Ghana: evidence from rural communities in central Ghana. measure evaluation PRH working paper series WP-12128. USAID/Measure evaluation, 2012.

8 Enuameh $\mathrm{Y}$, Nettey OE, Mahama E, et al. Family planning needs of adolescents in predominantly rural communities in the central part of Ghana. Open J Prev Med 2015;05:269-79.

9 Mccurdy RJ, Schnatz PF, Weinbaum PJ, et al. Contraceptive use in adolescents in sub-Saharan Africa: evidence from demographic and health surveys. Conn Med 2014;78:261-72.

10 Woog V, Susheela S, Alyssa B. Adolescent womens need for and use of sexual and reproductive health services in developing countries: Guttmacher Institute New York, 2015.

11 Ameyaw EK. Prevalence and correlates of unintended pregnancy in Ghana: analysis of 2014 Ghana demographic and health survey. Matern Health Neonatol Perinatol 2018;4:17.

12 World Health Organization. Orientation programme on adolescent health for health-care providers - Handout, 2020.

13 Gyan C. The effects of teenage pregnancy on the educational attainment of girls at Chorkor, a suburb of Accra. J Edu Soc Res 2013;3:53. doi:10.5901/jesr.2013.v4n3p53

14 Sedgh G, Singh S, Hussain R. Intended and unintended pregnancies worldwide in 2012 and recent trends. Stud Fam Plann 2014;45:301-14.

15 Owoo NS, Lambon-Quayefio MP, Onuoha N. Abortion experience and self-efficacy: exploring socioeconomic profiles of GHANAIAN women. Reprod Health 2019;16:117.

16 Ghana Statistical Service (GSS), Ghana Health Service (GHS), and ICF. Ghana maternal health survey 2017. Accra, Ghana: GSS, GHS, and ICF, 2018.

17 Ghana Statistical Service (GSS), Ghana Health Service (GHS), and Macro International. Ghana maternal health survey 2007, 2009.

18 Morhee R, Morhee E. Overview of the law and availability of abortion services in Ghana. Ghana Med J 2006;40:80-6.

19 Ghana Statistical Service (GSS), Ghana Health Service (GHS), ICF International. Ghana demographic and health survey 2014. Rockville: GSS, GHS, and ICF International, 2015.

20 Ghana Statistical Service (GSS), Ghana Health Service (GHS), and ICF Macro. Ghana demographic and health survey 2008, 2009.

21 Government of Ghana. Family planning 2020 commitment. family planning 2020, 2017.

22 Nations U. Transforming our world: the 2030 agenda for sustainable development, 2016.

23 Beson P, Appiah R, Adomah-Afari A. Modern contraceptive use among reproductive-aged women in Ghana: prevalence, predictors, and policy implications. BMC Womens Health 2018;18:157.

24 Wilson HW, Ameme DK, llesanmi OS. Contraceptive methods accessed in Volta region, Ghana, 2009-2014. International Scholarly Research Notices, 2017.

25 Boamah EA, Asante KP, Mahama E, et al. Use of contraceptives among adolescents in Kintampo, Ghana: a cross-sectional study. Open Access J Contracept 2014;5:7-15

26 Hall KS, Manu A, Morhe E, et al. Bad girl and unmet family planning need among Sub-Saharan African adolescents: the role of sexual and reproductive health stigma. Qual Res Med Healthc 2018;2:55.

27 Agyemang J, Newton S, Nkrumah I, et al. Contraceptive use and associated factors among sexually active female adolescents in Atwima Kwanwoma district, Ashanti region-Ghana. Pan Afr Med J 2019;32:182.

28 Nyarko SH. Prevalence and correlates of contraceptive use among female adolescents in Ghana. BMC Womens Health 2015;15:60.

29 Appiah F, Seidu A-A, Ahinkorah BO, et al. Trends and determinants of contraceptive use among female adolescents in Ghana: analysis of 2003-2014 demographic and health surveys. SSM Popul Health 2020;10:100554. doi:10.1016/j.ssmph.2020.100554 
30 Marrone G, Abdul-Rahman L, De Coninck Z, et al. Predictors of contraceptive use among female adolescents in Ghana. Afr J Reprod Health 2014;18:102-9.

31 Ghana Statistical Service (GSS). 2010 population and housing census: summary report of final results. Ghana statistical service Accra, 2012.

32 Hagan JE, Buxton C. Contraceptive knowledge, perceptions and use among adolescents in selected senior high schools in the central region of Ghana. JSR 2012;3:170-80.

33 Rokicki S, Merten S. The context of emergency contraception use among young unmarried women in Accra, Ghana: a qualitative study. Reprod Health 2018;15:1-10.

34 Grindlay K, Dako-Gyeke P, Ngo TD, et al. Contraceptive use and unintended pregnancy among young women and men in Accra, Ghana. PLoS One 2018;13:e0201663.

35 Makola L, Mlangeni L, Mabaso M, et al. Predictors of contraceptive use among adolescent girls and young women (AGYW) aged 15 to 24 years in South Africa: results from the 2012 national populationbased household survey. BMC Womens Health 2019;19:158.

36 Christofides NJ, Jewkes RK, Dunkle KL, et al. Early adolescent pregnancy increases risk of incident HIV infection in the eastern Cape, South Africa: a longitudinal study. J Int AIDS Soc 2014;17:18585

37 Ganle JK, Amoako D, Baatiema L, et al. Risky sexual behaviour and contraceptive use in contexts of displacement: insights from a crosssectional survey of female adolescent refugees in Ghana. Int J Equity Health 2019;18:127.

38 Rondini S, Krugu JK. Knowledge, attitude and practices study on reproductive health among secondary school students in Bolgatanga, upper East region, Ghana. Afr J Reprod Health 2009:13:51-66.

39 MacPhail C, Campbell C. 'I think condoms are good but, aai, I hate those things': condom use among adolescents and young people in a Southern African township. Soc Sci Med 2001:52:1613-27.

40 Sedgh G, Ashford LS, Hussain R. Unmet need for contraception in developing countries: examining women's reasons for not using a method. New York: Guttmacher Institute, 2016: 2. 2015-6.
41 Wang W, Staveteig S, Winter R, et al, eds. Women's marital status, contraceptive use, and unmet need in Sub-Saharan Africa, Latin America, and the Caribbean. ICF, 2017.

42 Okereke $\mathrm{Cl}$. Unmet reproductive health needs and health-seeking behaviour of adolescents in Owerri, Nigeria. Afr $\mathrm{J}$ Reprod Health 2010;14:43-54

43 Adanu RM, Tweneboah E. Reasons, fears, and emotions behind induced abortions in Accra, Ghana. Instit African Stud Res Rev 2004;20:1-9. doi:10.4314/rrias.v20i2.22910

44 Kwankye SO. Female adolescents and reproductive change in Ghana: evidence from an adolescent survey of two communities. African Population Studies 2013;21.

45 Baiden F, Amponsa-Achiano K, Oduro AR, et al. Unmet need for essential obstetric services in a rural district in northern Ghana: complications of unsafe abortions remain a major cause of mortality. Public Health 2006;120:421-6.

46 Aboagye PK, Gebreselassie H, Asare GQ. An assessment of the readiness to offer contraceptives and comprehensive abortion care in the greater Accra eastern and Ashanti regions of Ghana, 2007.

47 Aladago D, Boakye-Yiadom A, Asaarik M. The consequences of abortion restrictions for adolescents'healthcare in Ghana: the influence of Ghana's abortion law on access to safe abortion services. UDS Int J Develop 2019;6:1-9.

48 Republic of Ghana. National health insurance act (act 852). Accra, 2012.

49 Chandra-Mouli V, McCarraher DR, Phillips SJ, et al. Contraception for adolescents in low and middle income countries: needs, barriers, and access. Reprod Health 2014;11:1.

50 Chandra-Mouli V, Chatterjee S, Bose K. Do efforts to standardize, assess and improve the quality of health service provision to adolescents by government-run health services in low and middle income countries, lead to improvements in service-quality and service-utilization by adolescents? Reprod Health 2015;13:10.

51 Gonsalves L, Hindin MJ. Pharmacy provision of sexual and reproductive health commodities to young people: a systematic literature review and synthesis of the evidence. Contraception 2017:95:339-63. 